Available online on 15.12 .2018 at http://jddtonline.info
Journal of Drug Delivery and Therapeutics
Open Access to Pharmaceutical and Medical Research
anrestricted non-commercial use, provided the original work is properly cited
iDT

Open Access

Research Article

\title{
Formulation and evaluation of transdermal drug delivery system of verapamil hydrochloride
}

\author{
Marapur S C ${ }^{* 1}$, Wali D S ${ }^{1}$, Hunasagi B S ${ }^{2}$ Chetankumar M ${ }^{1}$, Patil R G ${ }^{1}$ \\ ${ }^{1}$ Dept. of Pharmaceutics, BLDEA's SSM College of Pharmacy and Research centre, B.L.D.E. University campus, Vijayapur-586 103, Karnataka, \\ India. \\ ${ }^{2}$ Dept. of Pharmacognosy, BLDEA's SSM College of Pharmacy and Research centre, B.L.D.E. University campus, Vijayapur-586 103, \\ Karnataka, India.
}

\begin{abstract}
The aim of this research was to develop and evaluate a matrix type of transdermal drug delivery system containing Verapamil Hydrochloride. The series of formulations containing Verapamil Hydrochloride were formulated by using different polymers like HPMC (hydrophilic), CAP (hydrophobic) and EC (hydrophobic) in different ratios by solvent evaporation technique. Propylene glycol and Dibutyl phthalate were used as plasticizers. The $20 \%$ and $40 \%$ of DMSO is used as the penetration enhancer. Formulated transdermal patches were physically evaluated for thickness, weight variation, drug content, flatness, tensile strength, folding endurance, and water vapour transmission rate. The in-vitro drug release study was carried out by using Franz diffusion cell. The data obtained from release study shows increased percentage of drug permeated in 20\% of DMSO containing formulation than $40 \%$ of DMSO containing formulation. Drug permeation is enhanced in the formulation containing high concentration of HPMC (VH1). The VH2 and VH6 helped in maintaining the rate of release at a constant level (20\% DMSO). But in case of $40 \%$ DMSO is used as the concentration of CAP increases the rate of permeation increases. Skin irritation study does not show any irritation on the skin of rabbit. There is no possible interaction between drug and polymers in FITR as well as DSC. XRD of selected formulation shows that drug present in the formulation is in crystalline form.
\end{abstract}

Keywords: Verapamil HCl, HPMC, EC, CAP, DMSO, TDDS, Solvent evaporation

Article Info: Received 14 Oct 2018; Review Completed 26 Nov 2018; $\quad$ Accepted 28 Nov 2018; Available online 15 Dec 2018

\section{Cite this article as:}

Marapur SC, Wali DS, Hunasagi BS, Chetankumar M, Patil RG, Formulation and evaluation of transdermal drug delivery system of verapamil hydrochloride, Journal of Drug Delivery and Therapeutics. 2018; 8(6-s):70-77

DOI: http://dx.doi.org/10.22270/jddt.v8i6-s.2081

\section{*Address for Correspondence:}

S C Marapur, Associate Professor,Dept. of Pharmaceutics, BLDEA'S SSM College of Pharmacy and Research Centre, Vijaypur-586101, Karnataka, India.

\section{INTRODUCTION}

The most preferred route of administration is oral route but oral route have some disadvantages like hepatic first pass metabolism, poor bioavailability and tendency to produce rapid blood level spikes and this leads to frequent dosing so to overcome these drawbacks there is a need for the development of new drug delivery system. ${ }^{1}$

TDDS are topically administered medicaments. Patches that deliver drugs for systemic effects at a predetermined and controlled rate. Transdermal patches are flexible pharmaceutical preparation of changeable sizes, containing, one or more active ingredients. Patches are intended to be applied to the unbroken skin in order to convey the active components to the systemic circulation after passing through the skin barriers.
Transdermal delivery not just provides controlled, continuous administration of the drug, but also allows constant input of drugs with short biological $1 / 2$ life and eliminates pulsed entry into systemic circulation, which often causes adverse side effects. Thus, a variety of forms of Novel drug delivery system such as TDDS, CRS, Transmucosal delivery systems etc. emerged ${ }^{2}$. Which improves the physiological and pharmacological response, avoiding the fluctuation in drug levels, inter and intra patient variations $\mathbf{1}^{\text {. }}$

The main goal of transdermal drug delivery system is to maximize the flux through the skin into the systemic circulation and simultaneously minimize the retention and metabolism of the drug in the skin ${ }^{3}$.

Verapamil hydrochloride is an L-type calcium channel blocker of the phenylalkylamine class. Given orally, 90 to $100 \%$ of verapamil is absorbed, but due to high first-pass 
metabolism, bioavailability is much poorer (10 to35\%). It is $90 \%$ bound to plasma proteins and it has a volume of distribution of 3 to $5 \mathrm{l} / \mathrm{kg}$. It gets metabolized in the liver into 12 inactive metabolites. $70 \%$ of metabolites get excreted in the urine and $16 \%$ in feces; 3 to $4 \%$ is excreted unaffected in urine. Metabolism is a nonlinear dependence between plasma concentration and dosage. Onset of action is 1 to 2 hours after oral dosage. t $1 / 2$ is 2.8 to 7.4 hours. $^{4}$

Hence, the proposed work involves the formulation and evaluation of transdermal drug delivery systems containing verapamil hydrochloride for the treatment of patients during hypertension and angina pectoris.

\section{MATERIALS AND METHODS}

Materials: Verapamil Hcl is received as gift sample from Micro labs Bangalore, Karanataka. Hydroxy propyl methyl cellulose (HPMC), Cellulose acetate phthalate and ethyl cellulose were purchased from Central drug house (p) ltd, Yarrow chem. Products, and Loba Chemicals pvt. Ltd. Mumbai, India. Di-butyl phthalate, propylene glycol, chloroform, dimethyl sulfoxide are purchased from Loba Chemicals pvt. Ltd. Mumbai, Finar chemical ltd and Central drug house (p) ltd . All other solvents and reagents were used as analytical grade.

Table 1: Formulation table for Verapamil HCl

\begin{tabular}{|c|c|c|c|c|c|c|c|c|c|c|c|c|}
\hline Ingrediens & VH1 & VH2 & VH3 & VH4 & VH5 & VH6 & VH7 & VH8 & VH9 & VH10 & VH11 & VH12 \\
\hline $\begin{array}{l}\text { Verapamil } \\
\mathrm{HCl} \text { mg }\end{array}$ & 100 & 100 & 100 & 100 & 100 & 100 & 100 & 100 & 100 & 100 & 100 & 100 \\
\hline HPMC mg & 500 & - & - & 200 & 200 & - & 500 & - & - & 200 & 200 & - \\
\hline CAP mg & - & 500 & - & 300 & - & 200 & - & 500 & - & 300 & - & 200 \\
\hline EC mg & - & - & 500 & - & 300 & 300 & - & - & 500 & - & 300 & 300 \\
\hline $\begin{array}{l}\mathrm{DBP} / \mathrm{PG} \\
(\mathrm{w} / \mathrm{v})\end{array}$ & $\begin{array}{l}40 \% \\
P G\end{array}$ & $\begin{array}{l}60 \% \\
\text { DBP }\end{array}$ & $\begin{array}{l}40 \% \\
\text { DBP }\end{array}$ & $\begin{array}{l}50 \% \mathrm{D} \\
\mathrm{BP}\end{array}$ & $\begin{array}{l}40 \% \text { DB } \\
\mathrm{P}\end{array}$ & $\begin{array}{l}40 \% \text { DB } \\
\mathrm{P}\end{array}$ & $40 \% \mathrm{PG}$ & $\begin{array}{l}60 \% \mathrm{D} \\
\mathrm{BP} \\
\end{array}$ & \begin{tabular}{|l}
$40 \%$ \\
DBP \\
\end{tabular} & $\begin{array}{l}50 \% \\
\text { DBP }\end{array}$ & $\begin{array}{l}40 \% \\
\text { DBP }\end{array}$ & $\begin{array}{l}40 \% \\
\text { DBP }\end{array}$ \\
\hline $\begin{array}{l}\text { Alcohol/ } \\
\mathrm{CHCl}_{3} \mathrm{ml}\end{array}$ & 10 & 10 & 10 & 10 & 10 & 10 & 10 & 10 & 10 & 10 & 10 & 10 \\
\hline DMSO & $20 \%$ & $20 \%$ & $20 \%$ & $20 \%$ & $20 \%$ & $20 \%$ & $40 \%$ & $40 \%$ & $40 \%$ & $40 \%$ & $40 \%$ & $40 \%$ \\
\hline
\end{tabular}

\section{Preparation of transdermal patch}

Transdermal patches containing Verapamil $\mathrm{HCl}$ was prepared by using mercury substrate method using different grade of polymers. The polymers used were Ethyl cellulose, Cellulose acetate phthalate and Hydroxy propyl methyl cellulose were taken in required quantity as shown in the table. About $10 \mathrm{ml}$ of chloroform or ethanol is added to solubilztion of polymers and kept it aside for few minutes for swelling of polymers. And after complete solubilization of the polymers in mixture of solvent, weighed quantity of Verapamil $\mathrm{HCl}$ was further added to the polymeric solution and mixed well. Finally required quantity of dibutyl phthalate or propylene glycol is added to the mixture, and vertexed. It was set aside cleaned petridish containing mercury and kept it aside for solvent evaporation. The rate of solvent evaporation is controlled by inverting a glass funnel over the petridish. After overnight, the dried films were taken out and stored in a desiccators.

\section{Evaluation of transdermal patches}

Physical Appearance: All the formulated transdermal patches were visually examined for colour, flexibility, homogeneity and smoothness 5 .

Thickness: Thickness of the patches were calculated at 5 different randomly selected spots on films using a screw gauge (micrometer). Such determination was performed for each formulation 5 .

Weight Uniformity: Each patch was weighed separately and average weight of three films was determined $\mathbf{6}$.

Folding endurance: A strip of specific are is to be cut evenly and repeatedly folded at the same place till it broke. The number of times the film could be folded at the same place without breaking gave the value of the folding endurance ${ }^{7}$.

Determination of Drug content: A sample of 1 sq.cm of the patch was cut and weighed precisely. Each sample was ISSN: 2250-1177 subjected to dissolve in $100 \mathrm{ml}$ of 7.4 phosphate buffer solution and magnetically stirred for $24 \mathrm{hrs}$. The absorbance of the solution is determined by using UV-VIS spectrophotometer at respective $\mathrm{nm}$. The total drug present in the patch of Verapamil $\mathrm{HCl}$ was determined ${ }^{8}$.

Fourier transform infrared spectrometry: The pure drug and a mixture of drug with the selected polymers were taken for the interaction study. For that pure drug and mixture of drug with the selected polymers were mixed separately with IR grade $\mathrm{KBr} / \mathrm{NaCl}$ in the ratio of 1:100. The base line correction was done by using dried $\mathrm{KBr} / \mathrm{NaCl}$. IR spectra of the mixture were taken over a wave number range of 4000 to $400 \mathrm{~cm}^{-1}$. The IR spectra of the pure drug and mixture of drug and polymers were carried out separately. Then obtained IR spectra were investigated for possible interaction between polymer and drug9.

Scanning electron microscopic studies: The films were mounted in the SEM instrument by using double sided adhesive tape. The coated films were observed under SEM (JEOL/EO, JSM- 6390, Kyoto, Japan) at the required magnification at room temperature. The specific acceleration voltage was used along with the secondary electron image as a detector to get images of the formulation by which surface morphology of the patches were determined.

X-Ray diffraction studies: The spectra of the sample was recorded by using Rigaku Miniflex II , X-ray diffractometer with $\mathrm{Cu}-\mathrm{NF}$ filtered $\mathrm{CuK}$ radiation. Quartz was used an a internal standard for calibration. The powder $\mathrm{x}$ - ray diffractometer was to a digital graphical assembly and computer with $\mathrm{Cu}-\mathrm{NF} 25 \mathrm{KV} / 20 \mathrm{~mA}$ tube as $\mathrm{CuK}$ radiation source in the $2 \theta$ range $0-50^{\circ} \mathrm{C}$.

Differential scanning calorimetric analysis: The samples were heated from $0-300^{\circ} \mathrm{C}$ at a heating rate of $10^{\circ} \mathrm{C} /$ min under argon or nitrogen atmosphere using a micro calorimeter (DuPont-9900, USA) and then thermo grams were obtained. 
Water vapour transmission: For these study vials of equal diameter was used as permeation cell. These cells were thoroughly washed and dried, about one gram of calcium chloride was taken in vials and the films were tightly attached over the brim with the help of adhesive. Then the vials were subjected to weighing. The accurately weighed vials are placed in the desiccators containing saturated solution of potassium chloride $(200 \mathrm{ml})$. The vials were taken out and weighed after every $24 \mathrm{hrs}$ up to 7 days of storage. From the increased in the weights, the rate of water vapour transmission was calculated.

Permeation Studies: Thermostatically controlled Franz diffusion cell assembly was used for carrying out the permeation studies. Excised rat epidermis was placed over the receptor compartment with dermis facing towards donor compartment. Samples were withdrawn from the sampling port at predetermined intervals and the same quantity of fresh buffer was replaced at the same time to maintain sink conditions. Phosphate buffer pH 7.4 was filled in receptor compartment. The temperature was maintained at $37 \pm 2{ }^{\circ} \mathrm{C}$ and stirring rate was $100 \mathrm{rpm}$. The diffusion studies were carried out for $24 \mathrm{hrs}$. Samples were analyzed spectro photometrically at absorption maxima of $278 \mathrm{~nm}$

Skin Irritation study: Skin irritation test is carried out on healthy rabbits (average weight 1.2 to $1.5 \mathrm{~kg}$ ). The dorsal surface $\left(50 \mathrm{~cm}^{2}\right)$ of the rabbit is to be cleaned by removing the hair from the dorsal surface by shaving. The prepared formulations can be applied over the skin. The patch is to be detached after $24 \mathrm{hr}$ and the skin is to be observed for irritation and oedma.

Stability studies: The stability studies of the formulations were carried out as per ICH guidelines. The samples were observed for physical changes like color, flexibility, etc.

\section{RESULT AND DISCUSSION}

The compatibility between Verapamil Hydrochloride and the selected polymers were found out by using FTIR spectroscopy.

The spectra of pure Verapamil Hydrochloride shows a distinctive peaks at $2990 \mathrm{~cm}^{-1} \mathrm{C}-\mathrm{H}$ stretching of methyl and methylene group, $2840 \mathrm{~cm}^{-1} \mathrm{C}-\mathrm{H}$ stretching of methoxy group, $2642.54 \mathrm{~cm}^{-1} \mathrm{~N}-\mathrm{H}$ stretching of protonated amine, $2236 \mathrm{C}=\mathrm{N} \mathrm{cm}^{-1}$ gr. Alkyl nitrile, $1591.90 \mathrm{~cm}^{-1}$ stretching of benzene ring and $1261.25 \mathrm{C}=0$ stretching. Similar peaks are observed in the combinations of pure drug and mixture of selected polymers with slight variations in $\mathrm{cm}^{-1}$. That implies there is no interaction between drug and polymers.

The physiochemical properties of the prepared formulations of Verapamil hydrochloride patches are tabulated. were thin, flexible, elastic, smooth and transparent/ translucent. The drug content uniformity of prepared formulations is in the following order: VH11> VH6 $>$ VH12> VH5 > VH8> VH7> VH2> VH1 > VH3> VH9> VH4> VH10. The values of drug content indicate that Verapamil Hydrochloride is uniformly distributed in the formulations.

Scanning electron microscopic study was performed to know the surface characteristics of the prepared formulations (patches). The SEM photomicrographs suggest that the membranes VH4, VH5 and VH6 have shown plain, uniform and smooth surface, while, VH6 formulation has shown relatively rough and dense surface than VH4 and VH5.

Differential scanning calorimetry: Pure powder of Verapamil Hydrochloride showed a melting endotherm at $148.24^{\circ} \mathrm{C}$. DSC test of VH5 showed a broad endotherm due to the existence of residual moisture in polymers. DSC thermogram of Verapamil Hydrochloride VH5 exhibits endothermic peaks at near to the pure drug temperature. This indicates that there is an absence of any interaction taking place between drug and polymers.

The X-ray diffractograms of pure drug Verapamil Hydrochloride shows sharp peaks between the $5 \theta$ to $28 \theta$, VH5 dummy patch doesn't show such peaks and VH5 patch containing drug shows peaks from $15 \theta$ to $28 \theta$. This indicates that the selected formulation having a drug in slight crystalline form.

Water vapor transmission (WVT) through the rate controlling matrix patches determines the permeability characteristics. All the prepared matrix type of transdermal patches were permeable to water vapours The WVT rates for VH1, VH2, VH3, VH4, VH5, VH6, VH7, VH8, VH9, VH10, VH11, VH12, were $0.081,0.042,0.016$, $0.031,0.028,0.091,0.062,0.018,0.020,0.022,0.016$ and 0.059 respectively.

The drug release studies from different patches were performed through the exercised rat abdominal skin and the results are listed. The cumulative amount of drug permeated per unit of surface area of the skin was plotted versus time, and the slope of the linear portion of the plot was calculated as the steady-state flux (JSS). The permeability coefficient (Kp), was then calculated with the following equation:

$$
\mathrm{Kp}=\mathrm{JSS} / \mathrm{CV}
$$

Where $\mathrm{CV}$ is the total concentration of the drug in the donor compartment.

In-vitro drug release studies were calculated for all the formulations and the percentage of drug permeations were calculated. VH1, VH2, VH3, VH4, VH5, VH6, VH7, VH8, VH9, VH10, VH11 and VH12 was 99.41, 96.65, 84.75, 90.71, $83.25,94.79,70.96,75.99,66.41,73.79,63.14$ and 60.98 at the end of $24^{\text {th }}$ hour respectively. As the concentration of HPMC increases the rate of permeation increases in the case of $20 \%$ DMSO used, but in case of $40 \%$ DMSO is used as the concentration of CAP increases the rate of permeation increases. The drug permeation study shows that the $\%$ of drug permeation is more in formulations containing $20 \%$ of DMSO than $40 \%$ of DMSO.

When primary skin irritation study is carried out on albino rabbits for the selected formulation VH6 indicates that there is no sign of erthyema or odema when compared with control patch. That indicates skin acceptability of these formulations for topical application.

The prepared formulations are stable in nature. There is no effectiveness in color, plasticity and drug content. 
Table 2: Physicochemical properties of Verapamil $\mathrm{HCl}$ patches

\begin{tabular}{|c|c|c|c|c|c|}
\hline Formulation & $\begin{array}{c}\text { Physical } \\
\text { appearance }\end{array}$ & $\begin{array}{c}\text { *Weight } \\
\text { SD in }+ \text { or }-\end{array}$ & **Thickness & $\begin{array}{c}\text { *Drug } \\
\text { content }\end{array}$ & $\begin{array}{c}\text { *Folding } \\
\text { endurance }\end{array}$ \\
\hline VH1 & ++ & $0.62(0.01)$ & $0.147(0.00) 15)$ & 94.51 & $>295$ \\
\hline VH2 & ++ & $0.75(0.01)$ & $0.203(0.00) 2)$ & 95.15 & $>225$ \\
\hline VH3 & ++ & $0.77(0.03)$ & $0.217(0.00) 41)$ & 93.86 & $>15$ \\
\hline VH4 & ++ & $0.76(0.02)$ & $0.173(0.00) 5)$ & 91.93 & $>250$ \\
\hline VH5 & ++ & $0.80(0.03)$ & $0.25(0.003)$ & 96.22 & $>270$ \\
\hline VH6 & ++ & $0.73(0.01)$ & $0.217(0.00) 34)$ & 96.65 & $>240$ \\
\hline VH7 & ++ & $0.68(0.04)$ & $0.147(0.00) 1)$ & 95.58 & $>295$ \\
\hline VH8 & ++ & $0.77(0.02)$ & $0.219(0.00) 14)$ & 95.79 & $>225$ \\
\hline VH9 & ++ & $0.83(0.03)$ & $0.240(0.00) 23)$ & 93.22 & $>15$ \\
\hline VH10 & ++ & $0.80(0.01)$ & $0.186(0.01)$ & 91.28 & $>250$ \\
\hline VH11 & ++ & $0.84(0.01)$ & $0.249(0.00) 24)$ & 96.65 & $>270$ \\
\hline VH12 & ++ & $0.78(0.02)$ & $0.235(0.00) 4)$ & 96.44 & $>240$ \\
\hline TH
\end{tabular}

The figure inside the parenthesis denotes the SD values

*Average of three observations.

**Average of five observations.

++ indicates satisfactory, + - indicates not satisfactory.

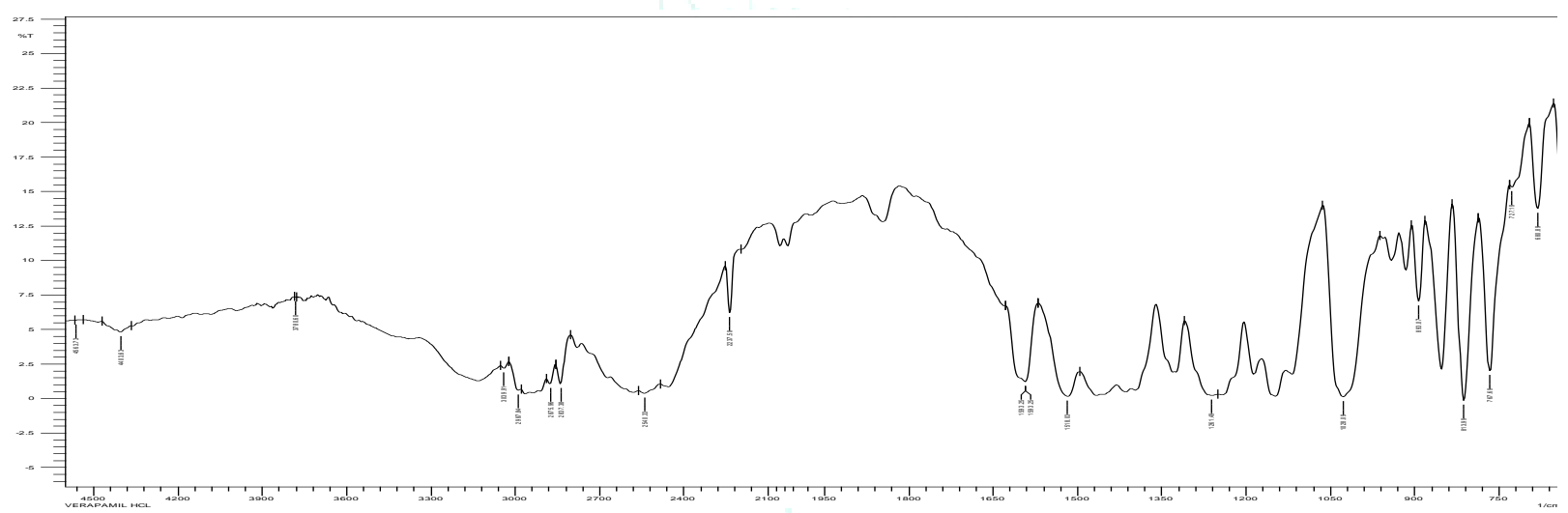

Figure 1: FITR of Verapamil HCl

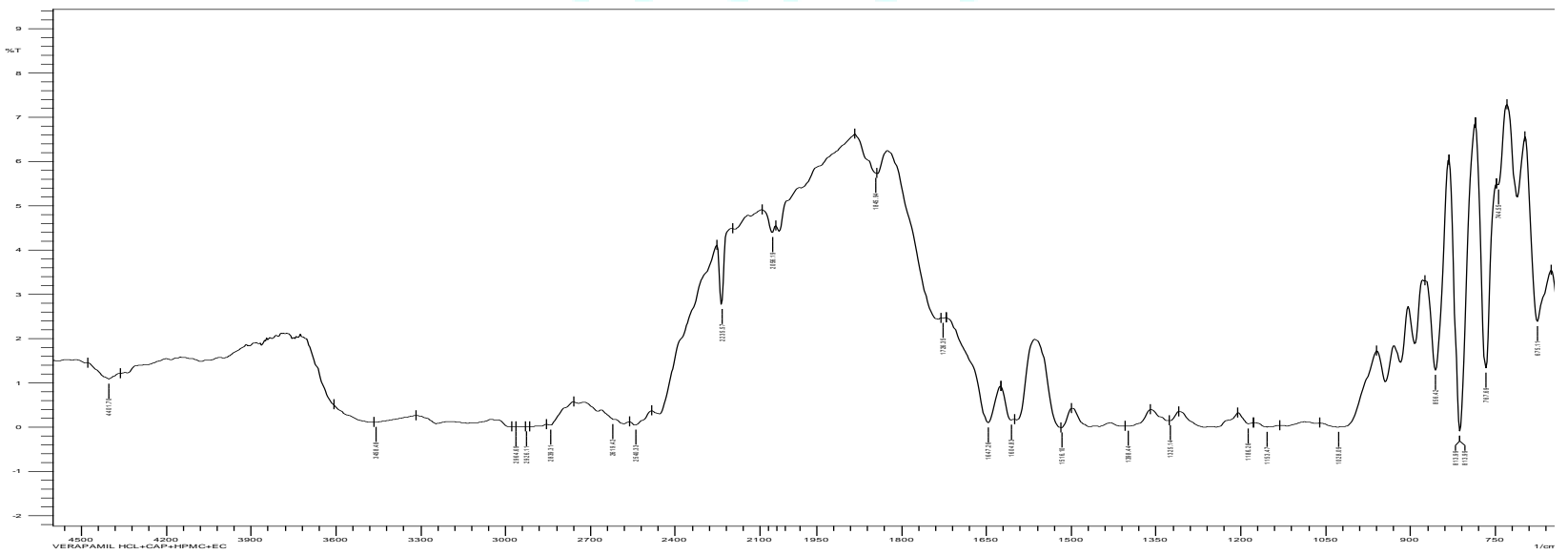

Figure 2: FTIR of mixture of Verapamil HCl , HPMC, CAP and EC 


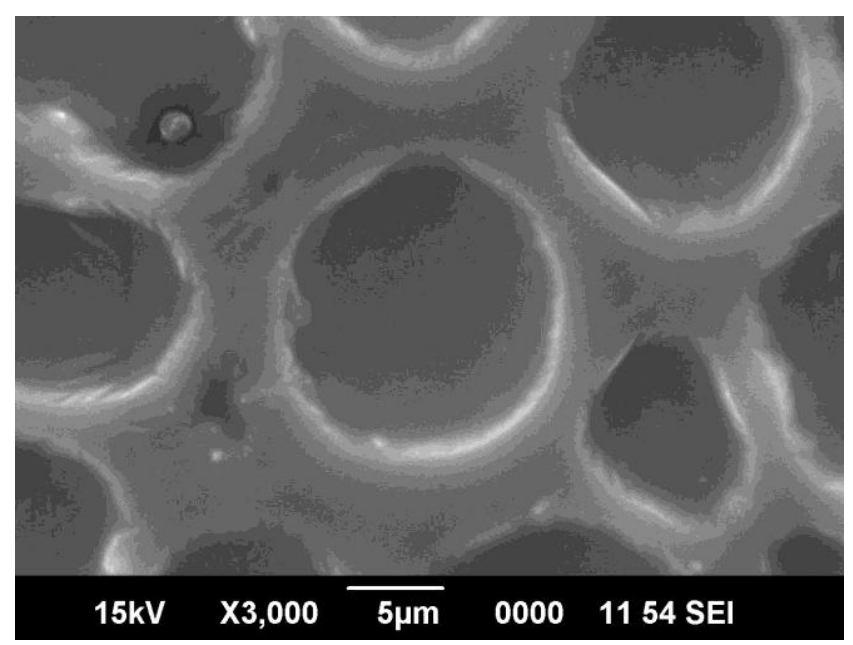

Figure 3: SEM Photograph of VH4 patch

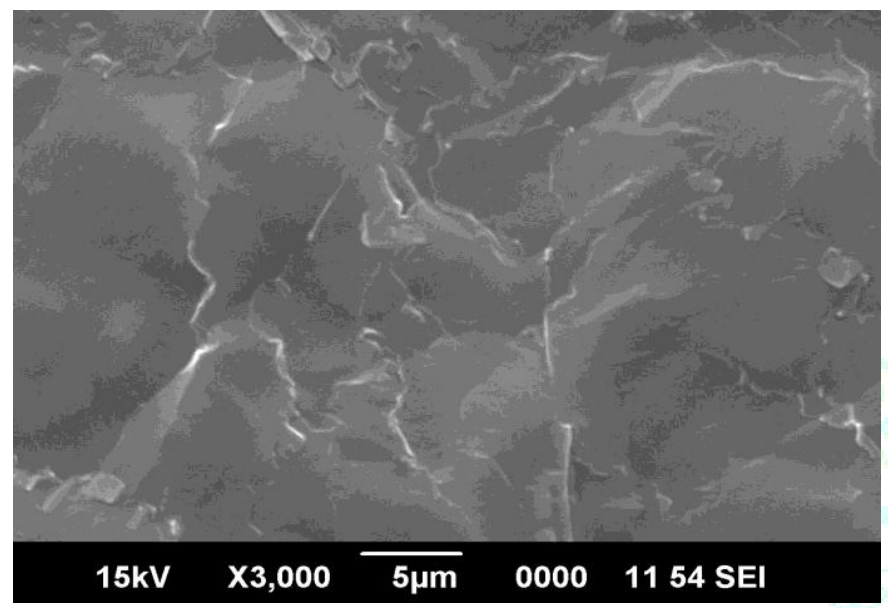

Figure 4: SEM photograph of VH5 patch

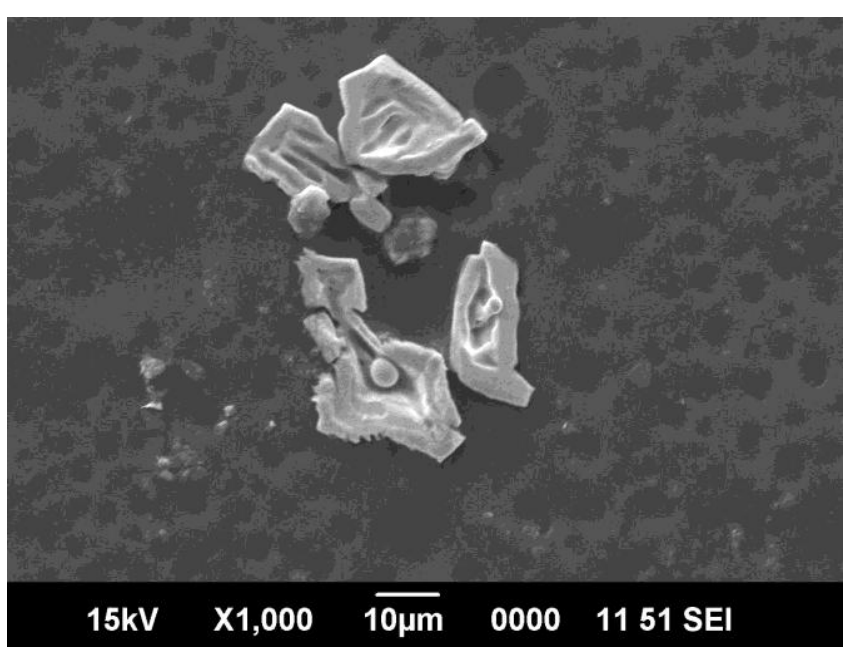

Figure 5: SEM photograph of VH6 patch

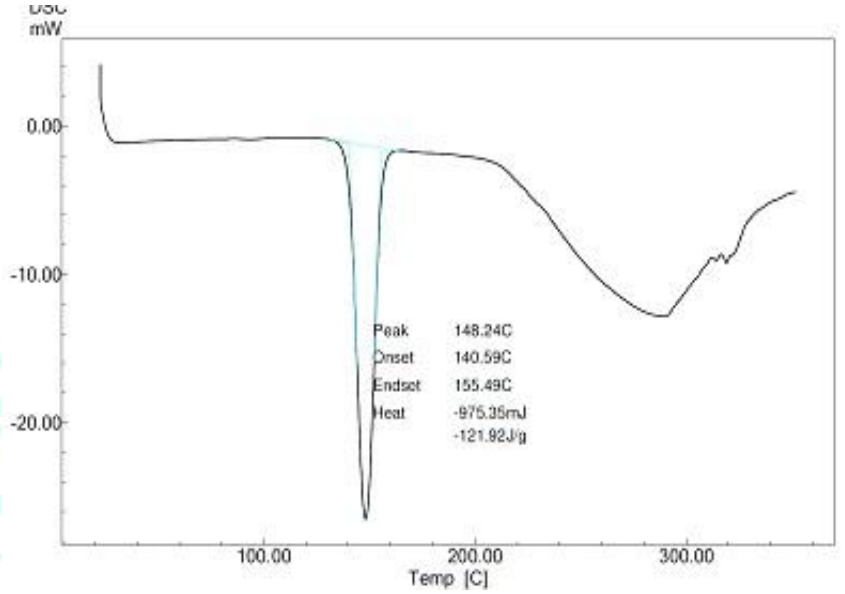

Fig.6 DSC thermogram of Verapamil HCl

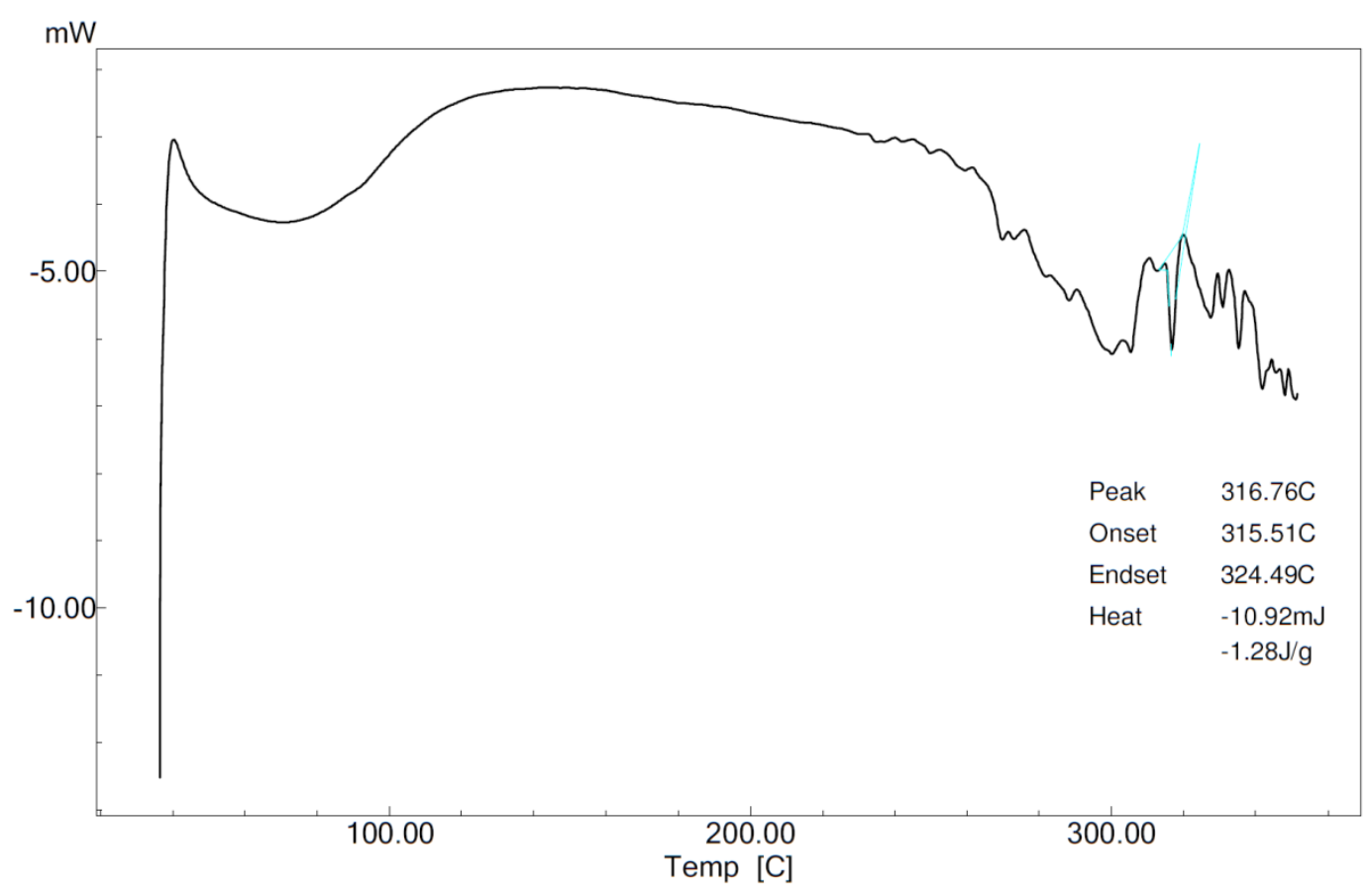

Figure 7: DSC thermogram of dummy patch VH5 


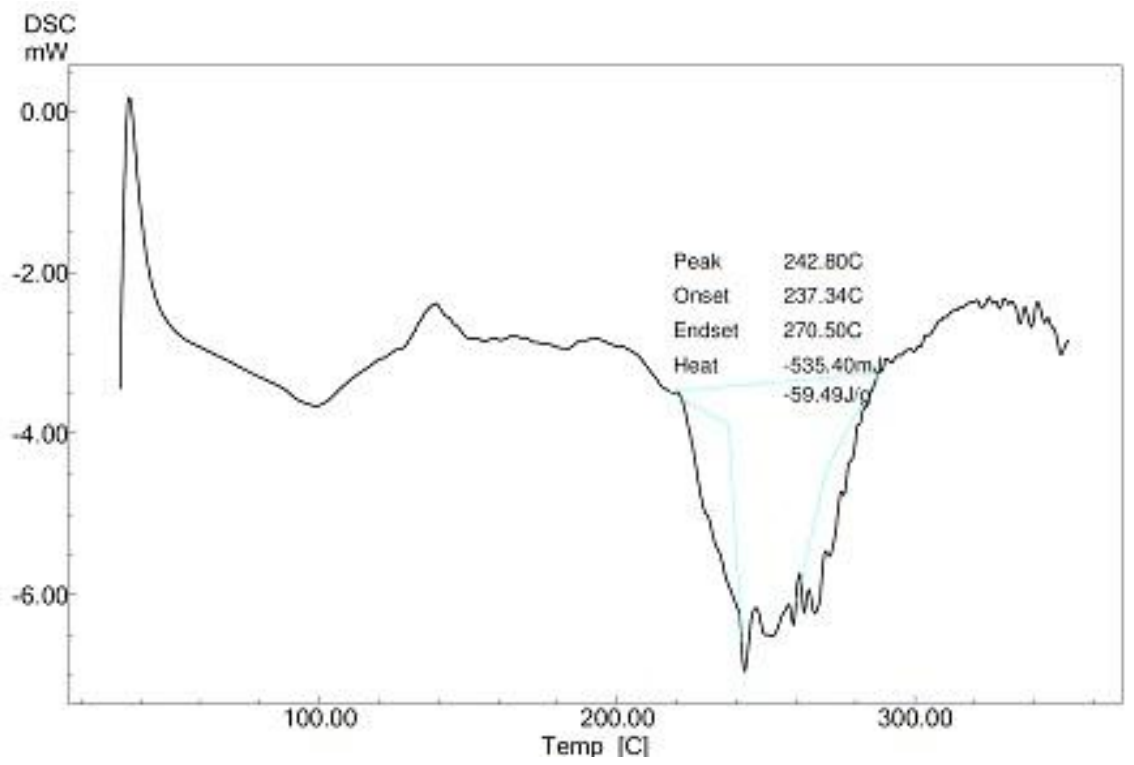

Figure 8: DSC thermogram of drug loaded patch of VH5

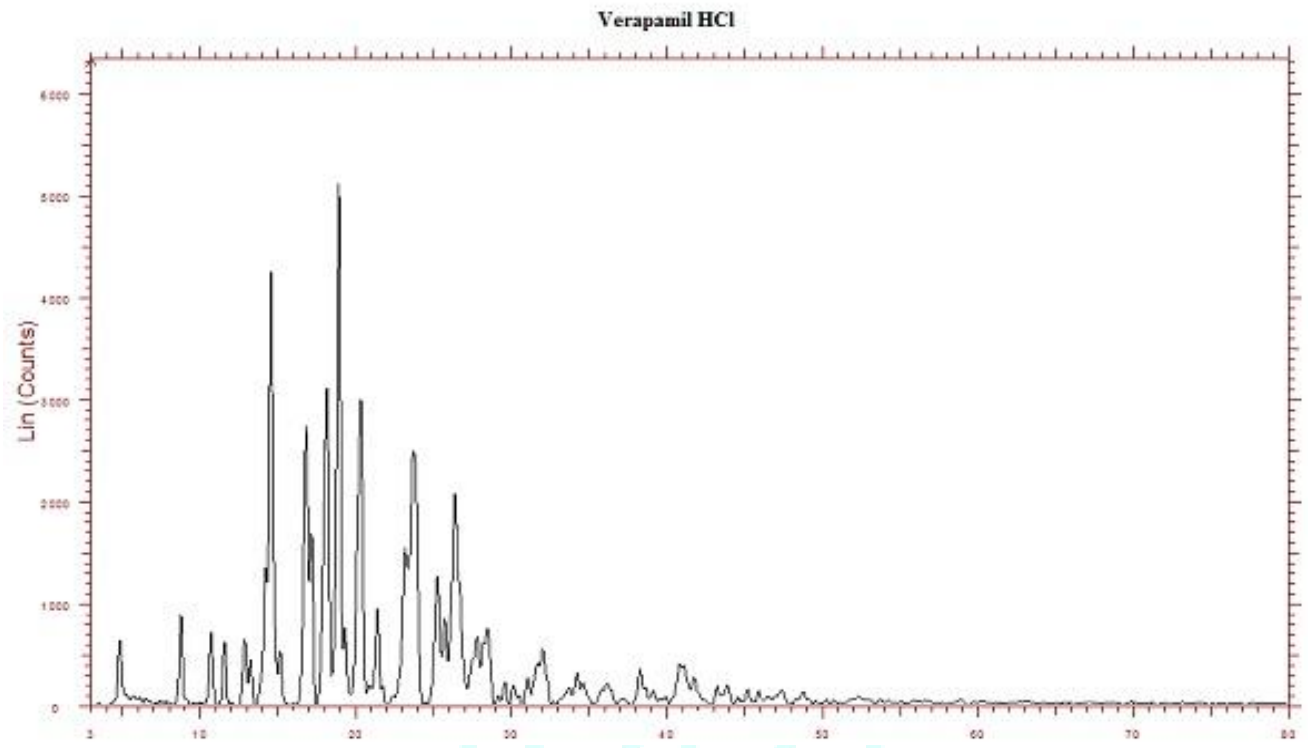

Figure 9: XRD diffraction of Verapamil HCl

XRD diffraction of dummy patch VH5

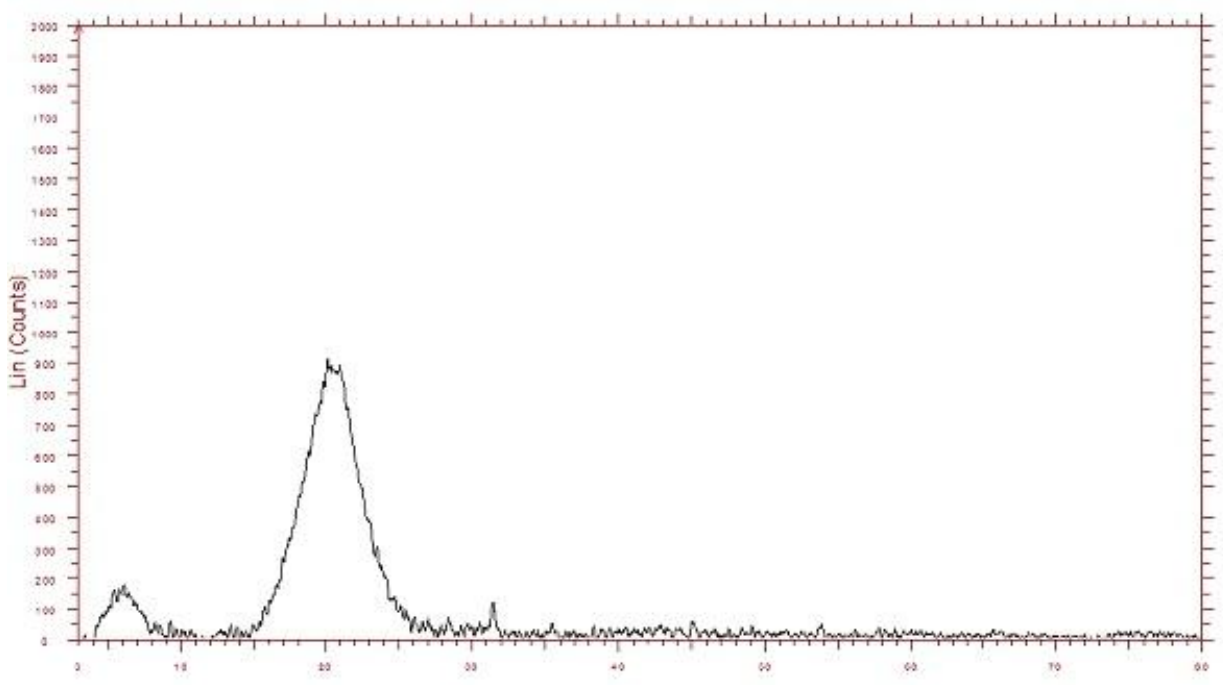

Figure 10: XRD diffraction of Verapamil HCl Patch without drug 
XRD of formulation VH5

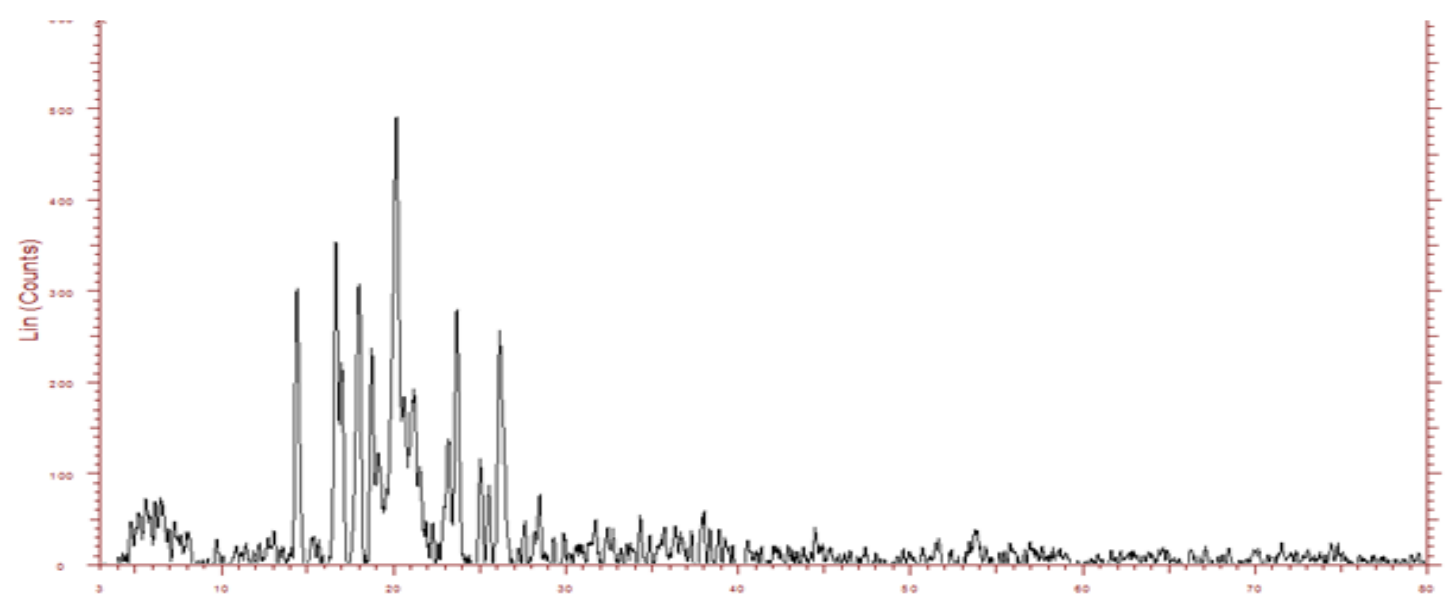

Figure 11: XRD diffraction of Formulation VH 5

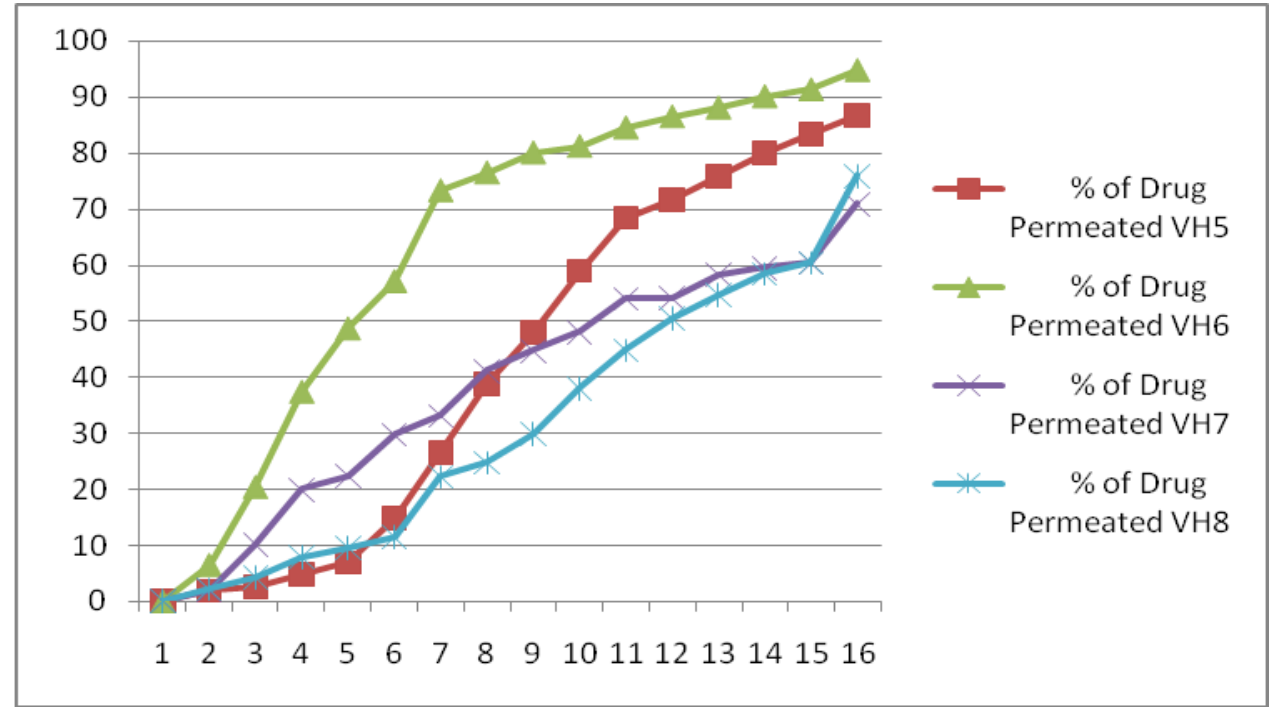

Figure 12: In-vitro permeation of verapamil hydrochloride of all formulated patches through the rat skin of formulation V5 to V8

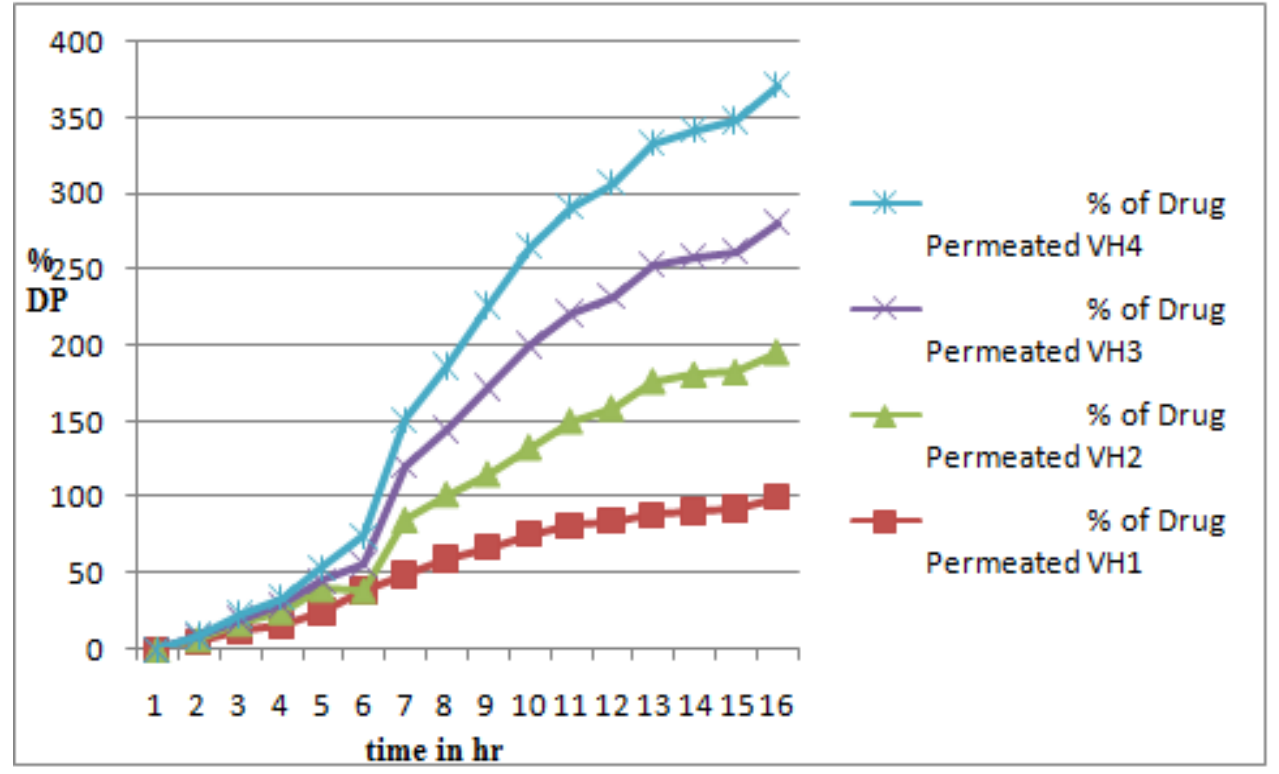

Figure 13: In-vitro permeation of verapamil hydrochloride of all formulated patches through the rat skin of formulation V1 to V4 
Table 3: Skin irritation test of selected verapamil hydrochloride patch on rabbit

\begin{tabular}{|c|c|c|}
\hline Formulations & Erythema & Edema \\
\hline VH6 & -- & -- \\
\hline
\end{tabular}

--: Nil, +: Mild, + +: Severe and +++: Very severe

\section{CONCLUSION}

In this research, attempts were made to formulate Verapamil Hydrochloride patches has been developed for the sustain transport of the drug action. This is done by using HPMC, CAP and EC as the rate retarding polymers using DMSO as the penetration enhancer. When those are subjected to evaluation, all the prepared transdermal patches were thin, elastic, smooth, flexible and transparent/ transculent. Uniformity and thickness were observed with the low SD values.

In-vitro drug permeation study is performed using Franz diffusion cells where drug is permeated through rat skin. The data obtained was plotted to know the mechanism of drug release. The drug release study was extended for 24 hrs. The incorporation of DMSO helped to enhance the penetration by detanglement of the lipid layer. Drug permeation is enhanced in the formulation containing high concentration of HPMC (VH1). The VH2 and VH6 helped in maintaining the rate of release at a constant level. Hence, a sustain release polymeric transdermal patch of verapamil hydrochloride was prepared which was able to deliver the drug at constant rate through the dermal barrier. Formulation containing $20 \%$ DMSO shows increased permeation than formulation containing $40 \%$ DMSO. Thus this study has shows potential results.

\section{REFERNCES}

1. Upadhyay G, Verma S, Parvez N, Sharma PK. Recent trends in transdermal drug delivery system - a review. Advances in Biological Research. 20148; (3):131-138. DOI: 10.5829/idosi.abr.2014.8.3.8446

2. J Ashok kumar1, Pullakandam1 N, S Lakshmana prabu, V Gopal. Transdermal drug delivery system: an overview. July August 2010; 3(2):49-54.

3. Bhowmik D, Rao KP, Duraivel S, Sampath Kumar KP. Recent approaches in transdermal drug delivery system. IC Journal No: 7725, 2013; 2(3):99-108.

4. Prashar M, Aggarwal G, Harikumar SL. Formulation and evaluation of transdermal drug delivery system of Simvastatin using natural and synthetic permeation enhancers. Der Pharmacia Lettre. 2014; 6 (5):358-368.

5. Patel HV, Bhatt JD, Patel NK. Design and development of transdermal drug delivery for anti-hypertensive drug using different polymeric system. International journal of pharmaceutical and chemical sciences 2013; 2(2):492-494.

6. Hafeez A, Dr Jain U, Singh J, Maurya A, Rana L Recent advances in transdermal drug delivery system (tdds): an overview. Journal of Scientific and Innovative Research. 2013; 2(3):695-709

7. Rao NR, Askulla S, Bhavya B, Prasoona Ch, Koppu P. Design and evaluation of glipizide transdermal patches. International Journal of Research in Pharmaceutical and Biomedical Sciences. 2011; 2(4):1620-1633

8. Bangale GS, Rathinaraj BS, Rajesh KS, Shinde GV, Umalkar DG, Rajveer CH et.al, Design and evaluation of transdermal films of atenolol. J. Chem. Pharm. Res. 2010; 2(3):593-604.

9. Sood J, Kaur V, Pawar P. Transdermal delivery of verapamil hcl: effect of penetration agenton in vitro penetration through rat skin. Journal of Applied Pharmaceutical Science. 2013; 3(03):044-051. DOI: 10.7324/JAPS.2013.30309 